\title{
Structural Behavior of Reinforced Hybrid Concrete Columns under Biaxial Loading
}

\author{
Alaa Hussein Al-Zuhairia (D), Ali Hussein Ali Al-Ahmed ${ }^{a}$, Ammar N. Hanoon ${ }^{b}$ (D) Ali A. Abdulhameed ${ }^{\text {* }}$ (iD \\ ${ }^{a}$ Civil Engineering Department, College of Engineering, University of Baghdad, Baghdad 10071, Iraq. Email: \\ alaalwn@coeng.uobaghdad.edu.iq, dr.ali-alahmed@coeng.uobaghdad.edu.iq \\ b Department of Reconstruction and Projects, University of Baghdad, Baghdad 10071, Iraq. Email: anh@uobaghdad.edu.iq, \\ aliadel@uobaghdad.edu.iq \\ * Corresponding author
}

https://doi.org/10.1590/1679-78256640

\begin{abstract}
The study aims to investigate the behaviour of reinforced hybrid concrete columns consisted of two fullybonded concretes subjected to biaxial loading. Experimental tests were conducted on 5 square columns of $200 \mathrm{~mm}$ side dimensions. Two columns were cast from one type of concrete but with varied strength. The other three specimens were cast by hybrid concrete with different hybrid's ratios. The study also comprised the derivation of an analytical model, simulating the behaviour of the tested column by numerical models, and statistical evaluation. Whereas a computer program was constructed to evaluate the ultimate strength of hybrid columns and finite element models were executed for the numerical analysis. Both results were compared with the experimental outcomes and good agreement was observed. The results revealed an increase in the ultimate load of hybrid columns by $33.5 \%$ as compared with conventional columns. Also, the ultimate load increased by $38 \%$ with decreasing the hybrid's ratio to 0.16 . It was concluded that hybrid columns with small hybrid's ratios sustain higher loads, moments and exhibited fewer axial strains.
\end{abstract}

\section{Keywords}

Hybrid concrete column, Analytical model, Finite element analysis, Biaxial loading, Interaction diagram

\section{Graphical Abstract}

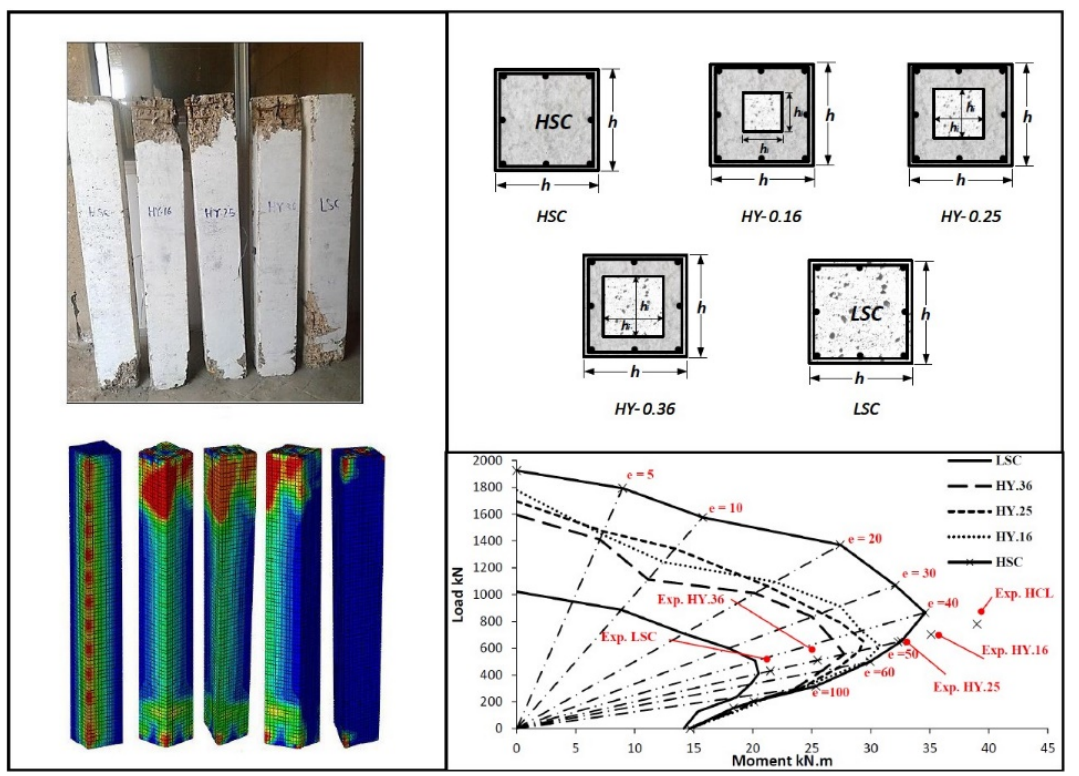

Received July 03, 2021. In revised form July 12, 2021. Accepted July 12, 2021. Available online July 14, 2021. https://doi.org/10.1590/1679-78256640

(a) Latin American Journal of Solids and Structures. ISSN 1679-7825. Copyright @ 2021. This is an Open Access article distributed under the terms of the Creative Commons Attribution License, which permits unrestricted use, distribution, and reproduction in any medium, provided the original work is properly cited. 


\section{INTRODUCTION}

Reinforced Concrete (RC) columns are structural members used mainly to carry compression loads. They have relatively small cross-sectional dimensions as compared with their height. RC columns are conventionally composed of steel reinforcing cages embedded in concrete (Abdualrahman and Al-Zuhairi, 2020a, Abdualrahman and Al-Zuhairi, 2020b). Nowadays, many researchers studied several types of nonconventional RC columns that used in structures such as composite columns, hollow columns and hybrid columns, as shown in Figure 1. These types of columns can be executed from one or two types of concrete. Structural combining of these types of materials can result in highly efficient and lightweight columns. This technique also offers benefits in terms of construction time-saving. However, some researchers studied the structural behaviour of tubular RC columns such as (Han et al., 2009; Yuan et al., 2018; Alshimmeri, 2016). In Figure 1(a), the concrete in the steel tube differs from the outside concrete without attachment between them. As well, many researchers studied the behaviour of RC hollow columns as displayed in Figure 1(b) with or without infill materials (Hadi and Le, 2014). Hybrid Columns (HC) are made from low strength concrete core jacketed with an outer skin made of high strength concrete. These columns can play a featured role in sustainability issues. The columns can be utilized effectively to recycle the crushed concrete wastes as the coarse aggregate of the inner concrete core. In this position, the problem of concrete carbonation that surely is faced in recycled concrete usage will be eliminated by exclusion this concrete from the area of existence of steel reinforcement, the most affected component by this problem. Thus, steel reinforcing rebars will remain protected from corrosion by the passive protection provided by the outer concrete despite the use of recycled concrete in the inner core.

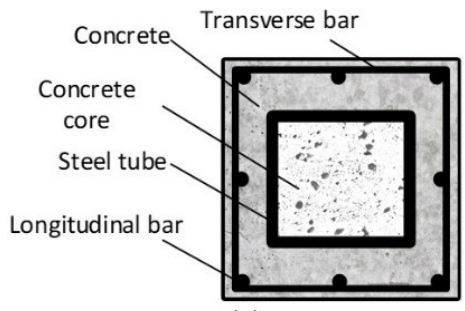

(a)

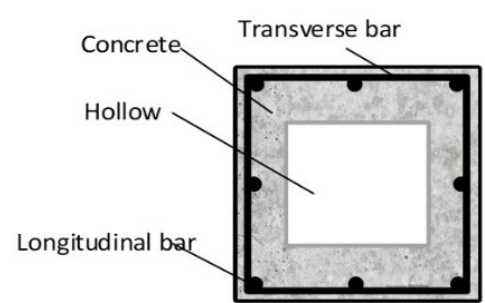

(b)

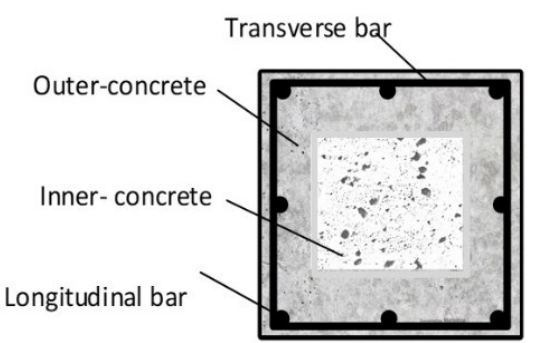

(c)

Figure 1. Types of composite RC columns: (a) Steel tube RC column; (b) Hollow RC column; (c) Hybrid RC column.

Based on available previous studies, two methods were observed to produce hybrid concrete columns: the normal (or low) strength concrete is made as inner core either confined by fibre reinforced concrete or high strength concrete without fibre materials, i.e., the column is made with two different concrete types (Wu et al., 2018; Resheq; 2018, Hamid et al., 2020; Ali, 2020). In both methods, the outer skin and inner core are interacted either by the full bond between the two concrete layers or by a partially bond between them. If the column is constructed continuously at one time, the chemical-physical interaction that happened at the interface of the two concretes leads to mutual bonding between them (Resheq, 2018; Hamid et al., 2020). Three primary factors contribute to the bond strength; natural adhesion, friction between different layers and the use of reinforcements (Dybet and Watach, 2017). On the other hand, the behaviour of $\mathrm{HC}$ with partial bonding between concrete layers was also studied by other researchers. In these columns, the concrete layers are connected either by resin materials or by shear keys (Wu et al., 2018; Ali, 2020; Abdulhameed and Said, 2019). These studies are closer to the topic of strengthening or repairing existing columns.

Hybrid columns can play an important role in the issue of sustainability in which they can be utilized effectively to recycle concrete waste after crushing as a coarse aggregate of the inner concrete core. In this position, the concrete carbonation problem that surely will be faced in recycled concrete usage can be eliminated by excluding this concrete out from the area of existence of reinforcing steel rebars, which is the most affected component by this problematic 
phenomenon. Thus, steel reinforcing rebars will remain protected from corrosion by the passive protection provided by the outer concrete despite the use of recycled concrete in the inner core.

Until the preparation of this paper, no obtainable information regarding the behaviour of hybrid concrete columns under the effect of biaxial loading is found available. Consequently, there is a lack of knowledge regarding the behaviour of biaxially loaded hybrid concrete columns with a full bond between concrete layers. This study aims to present experimental, analytical and numerical results of biaxially loaded $\mathrm{HC}$ with full interaction between inner and outer concrete layers. From these results, the general behaviour of such columns can be realized. The analytical study that was conducted on two conventional reinforced concrete and three hybrid concrete columns subjected to biaxial loading was starting from simple hypotheses of linear strain distribution and ending with developing a computer program to evaluate the strength and deformation behaviour of hybrid columns. Besides, all RC columns were analyzed by the finite element method via the ABAQUS program.

\section{MATERIALS AND METHODS}

\subsection{RC column specimens}

To study the actual structural behaviour of HC columns, a total of five RC column specimens were constructed and tested under biaxial loading. All RC column specimens have a square cross-section of $200 \mathrm{~mm}$ side dimension and $1200 \mathrm{~mm}$ height. Two of these specimens were conventional RC columns made from Low Strength Concrete (LSC) of $\mathrm{fc}^{\prime}=22 \mathrm{MPa}$ and High Strength Concrete (HSC) of $\mathrm{fc}^{\prime}=50 \mathrm{MPa}$ mixes. The other three specimens were produced as hybrid columns with different hybrid's ratios. The hybrid's ratio is assumed as the squared ratio of the inner core width (hi) to the total width of the column (h), as shown in Figure 2. Eight deformed steel rebars of $10 \mathrm{~mm}$ diameter were used as longitudinal reinforcement corresponding to a steel ratio of $1.65 \%$ and a $6-\mathrm{mm}$ deformed steel rebar was used for lateral reinforcement spaced at $100 \mathrm{~mm}$. The characteristics of tested column specimens and hybrid's ratio are listed in Table 1.

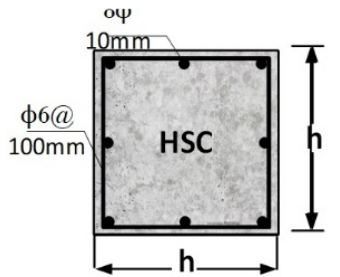

(a) HSC

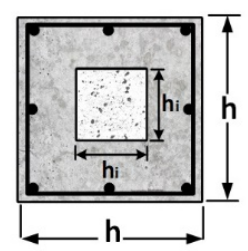

(b) HY-0.16

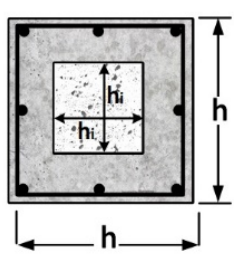

(c) HY-0.25

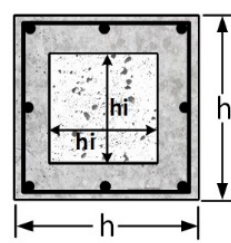

(d) HY-0.36

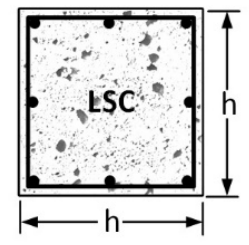

(e) LSC

Figure 2. Details of column specimens.

Table 1. Column specimens' details

\begin{tabular}{|c|c|c|c|c|c|}
\hline \multirow{2}{*}{ Column designation } & \multicolumn{2}{|c|}{ Inner concrete } & \multicolumn{2}{|c|}{ Outer concrete } & \multirow{2}{*}{ Hybrid's ratio (hi /h) } \\
\hline & Concrete Type & hi $(\mathrm{mm})$ & Concrete type & $h(\mathrm{~mm})$ & \\
\hline LSC & LSC & 0 & LSC & 200 & - \\
\hline HSC & HSC & 0 & HSC & 200 & - \\
\hline HY.16 & LSC & 80 & HSC & 200 & 0.16 \\
\hline HY.25 & $L S C$ & 100 & HSC & 200 & 0.25 \\
\hline HY.36 & $L S C$ & 120 & HSC & 200 & 0.36 \\
\hline
\end{tabular}




\subsection{Concrete mixes and material properties}

Ordinary Portland cement, river sand with fineness modulus of 2.84, crushed gravel with a maximum size of $9.5 \mathrm{~mm}$ and tap water were used for LSC mix production. In addition to these materials, a high-performance concrete superplasticizer was used to produce an HSC mix. The two concrete mixes were designed and prepared to produce the experimental RC column specimens. LSC mix was proportioned according to the ACl 211.1-2017. While the HSC mix was designed according to the ACI 211.4R-2017. Table 2 shows the quantities of materials per unit volume $(\mathrm{kg} / \mathrm{m} 3)$ for the two mixes.

To evaluate the mechanical properties of concrete mixes, uniaxial compression and splitting tensile strength tests were conducted on $150 \mathrm{~mm}$ cylinder specimens according to ASTM C39-18 and ASTM C496-11; respectively. In addition, the secant modulus of elasticity (Ec) was measured by the standard test carried out on $150 \mathrm{~mm} \times 300 \mathrm{~mm}$ cylindrical specimens according to ASTM C469-14. The average measured values of Ec were $24120 \mathrm{MPa}$ and $33065 \mathrm{MPa}$, for LSC and HSC, respectively. The test of control specimens was done using a compression machine with a capacity of (2000 kN) in the Structural Engineering Laboratory at the University of Baghdad as shown in Figure 3. Deformed steel rebars of the nominal diameter of $10 \mathrm{~mm}$ that used as longitudinal reinforcement were tested according to EN 10002.1-2001. The results of yield and tensile strength were $532 \mathrm{MPa}$ and $675 \mathrm{MPa}$ which is conformable with BS 4449-97 (grade 460). The ties were made of $\varphi 6 \mathrm{~mm}$ plane steel wire having an average yield strength of $263 \mathrm{MPa}$ and average tensile strength of $334 \mathrm{MPa}$ which satisfies the requirements of BS 4449-97 (grade 250).

Table 2. Concrete mix proportions for $1 \mathrm{~m}^{3}$ of Concrete

\begin{tabular}{|c|c|c|c|c|c|c|}
\hline \multirow{2}{*}{$\begin{array}{l}\text { Concrete mix } \\
\text { designation }\end{array}$} & $\boldsymbol{f}_{c}^{\prime}$ & Cement & Sand & Gravel & Water & Admixture \\
\hline & $\mathrm{MPa}$ & (kg) & (kg) & (kg) & (kg) & liter \\
\hline HSC & 50 & 457 & 647 & 1085 & 184 & 5.0 \\
\hline LSC & 22 & 345 & 814 & 864 & 228 & - \\
\hline
\end{tabular}

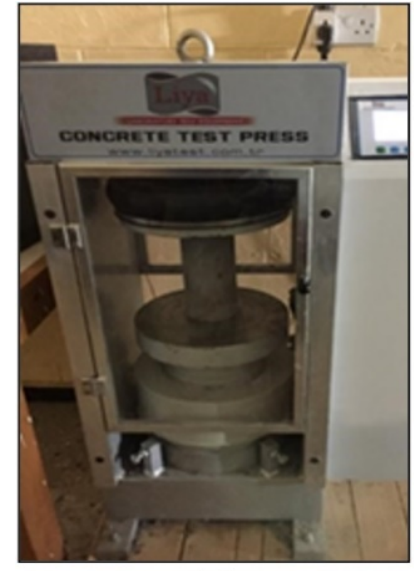

(a)

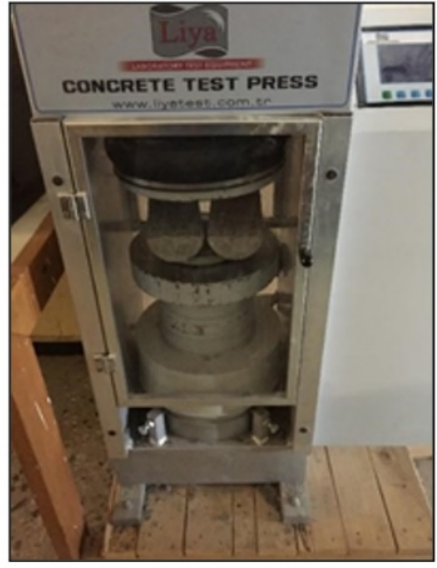

(b)

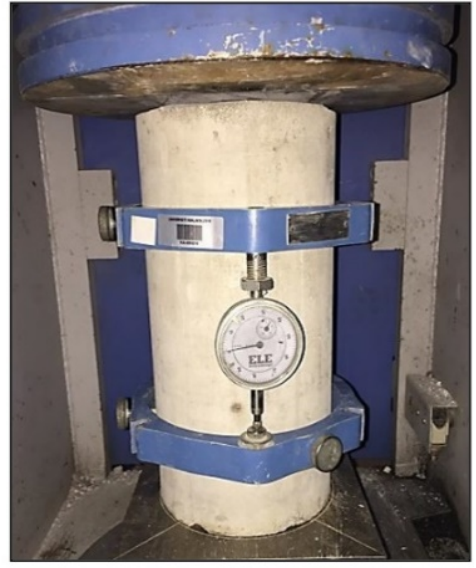

(c)

Figure 3. Testing of control specimens: (a) Compressive strength test; (b) Splitting tensile strength test; (c) Modulus of elasticity test.

\subsection{Casting of RC column specimens}

A steel mould was fabricated to cast RC column specimens. The mould consists of three parts, the first part is the mould base which is a square steel plate with $8 \mathrm{~mm}$ thickness and $800 \mathrm{~mm}$ side dimensions. Three square grooves were centrically created on the steel base to receive the hollow steel sections that will be responsible for forming the inner concrete part. The other two parts were manufactured as two square halves made from a $6 \mathrm{~mm}$ steel plate that was connected by bolts to form a $200 \mathrm{~mm}$ square steel tube that is going to be connected to the steel base utilizing bolts. The details of the steel mould, as well as the reinforcement cage, is displayed in Figure 4. 

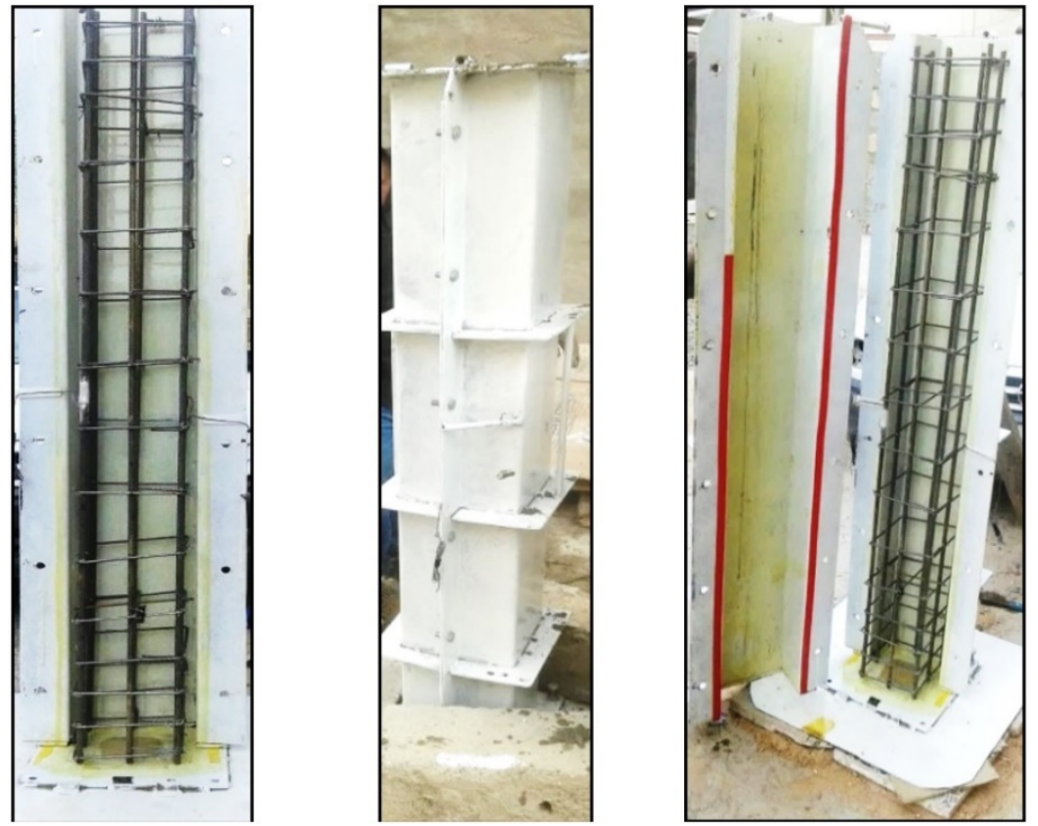

Figure 4. Steel mould used for column casting and the reinforcement cage.

All column specimens were cast vertically. The conventional two RC columns (HSC \& LSC) were cast at one time without using a central steel tube. While, the other hybrid RC columns were produced by inserting a square hollow steel tube with a side dimension of 80,100 or $120 \mathrm{~mm}$ inside the mould so that its lower end will be received by the corresponding groove of the steel base as shown in Figure 5. In addition, the top of the inner hollow steel section is laterally supported to the top sides of the outer steel mould using four adjusting bolts to prevent any lateral movement and providing the ability to pull out the inner steel section easily. The HSC layer was cast firstly in the space between the inner steel tube and the outer mould to about one-third of the mould height, then the LSC was cast inside the inner hollow steel section to the approximate same level of outer HSC. After that, the inner steel tube was moved carefully up to a quarter of steel mould height. This process was repeated twice so that the whole $\mathrm{HC}$ was constructed and the inner steel tube was drawn completely. By this construction procedure, the two types of concrete in $\mathrm{HC}$ have fully interacted. The steps of HC production were schematically drawn as shown in Figure 5.

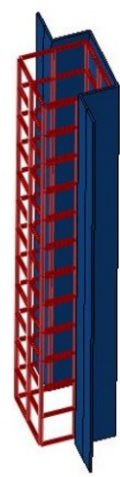

(a)

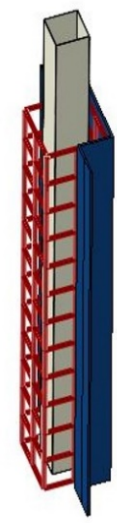

(b)

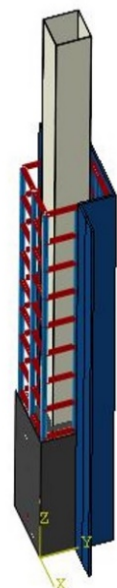

(c)

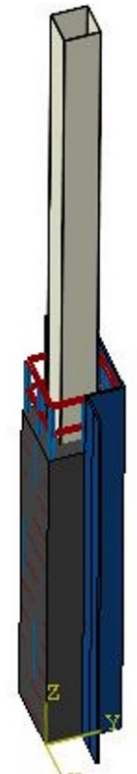

(d)

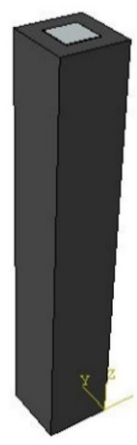

(e)

Figure 5. Casting steps of HC columns: (a) Mold assembly \& reinforcement steel gauge placement; (b) Inserting the inner square hollow steel tube; (c) Casting the 1st stage of HSC and LSC; (d) Moving up the inner tube \& casting the 2nd stage of HSC and LSC; (e) Complete HC specimen. 


\subsection{Test setup and boundary conditions}

All column specimens were tested using the loading frame shown in Figure 6 at the University of Baghdad-structural engineering laboratory under biaxial loading with an eccentricity of $50 \mathrm{~mm}$ for both $\mathrm{x}$ and $\mathrm{y}$ directions, (i.e., $\mathrm{ex}=\mathrm{ey}=50 \mathrm{~mm}$ ). So that the normalized eccentricity (e/h) was constant and equals 0.25 for all column specimens. The loading frame was originally designed and manufactured for a maximum force of $2000 \mathrm{kN}$ that applied by a hydraulic jack of $240 \mathrm{~mm}$ internal diameter fixed at the base of the frame and connected to a manual hydraulic pump of a maximum pressure capacity of $45 \mathrm{MPa}$ (450 bar). The hydraulic pump was supplied by a calibrated pressure gage and three valves provided in line of pressure hose, one for controlling the loading speed, and others were created to control the direction of hydraulic flow. These valves were operated manually and set up in such a way to hold the load at any particular stage if necessary. Both ends of the loading frame used for testing specimens were arranged as pinned ends with the capability to eccentric load.
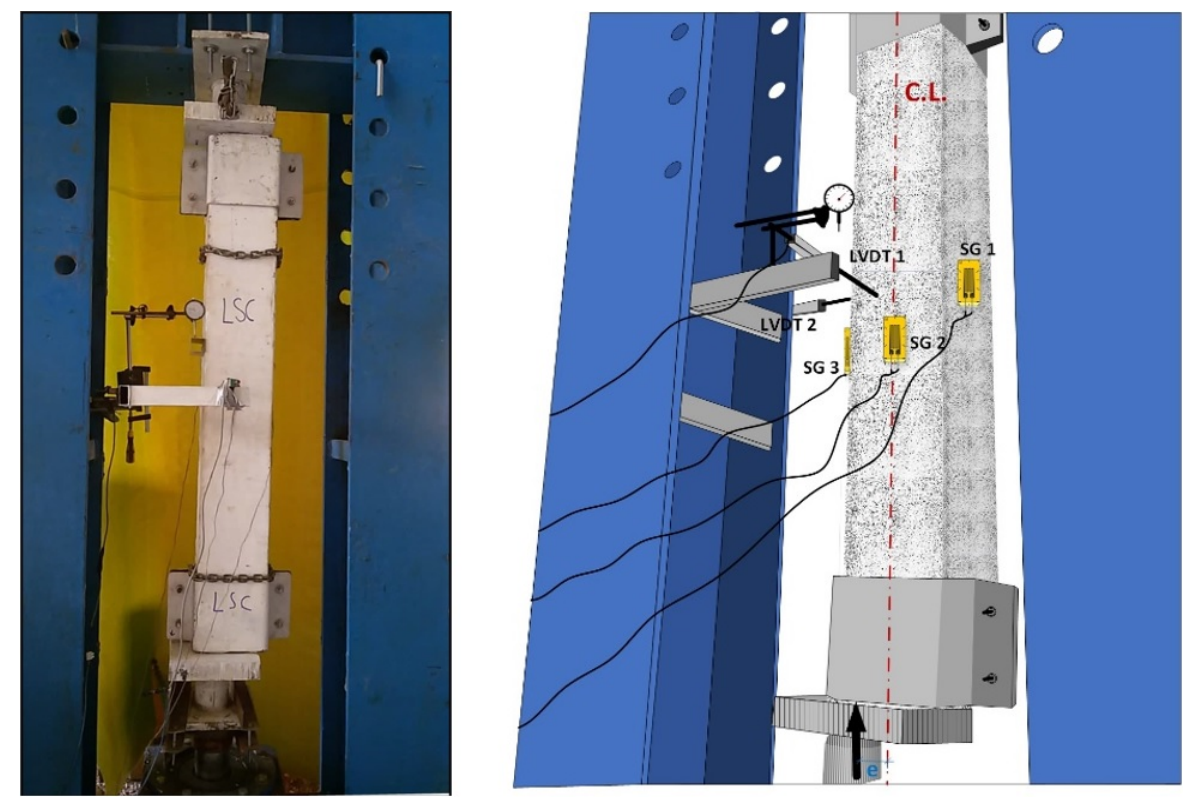

Figure 6. Test setup.

\section{ANALYTICAL AND NUMERICAL MODELS}

\subsection{Analytical model}

The goal of this part is to develop a computer program able to evaluate the strength capacity of HC based on the discrete element method. This method has been used by some researchers such as (Hsu, 1989) for the analysis of biaxially loaded conventional RC columns. In this study, the proposed computer program was written via MATLAB coding R2015b.In the present model, the effect of longitudinal bars, distribution of lateral reinforcement and concrete confinement were taken into consideration with adopting the stress-strain curve of confined concrete proposed by (Mander et al., 1988; Bouafia et al., 2014). The present method is based on strain compatibility, forces equilibrium and assuming plane section before bending remains plane after bending and full bond between concrete and steel reinforcement.

In the discrete element method, the cross-section of the column was divided into several small elements (or cells) in both directions, as shown in Figure 7. According to the equilibrium conditions, the axial load ( $N$ ) and bending moments $\mathrm{Mx}, \mathrm{My}$ can be expressed in the forms presented in the following equations:

$N=\int_{A_{c i}} \bar{E}_{c i} \cdot \varepsilon_{c i} d A_{c i}+\int_{A_{c o}} \bar{E}_{c o} \cdot \varepsilon_{c o} d A_{c o}+\sum_{i=1}^{n s} \bar{E}_{s i} \cdot \varepsilon_{s i} A_{s i}$

$M_{x}=\int_{A_{c i}} \bar{E}_{c i} \cdot \varepsilon_{c i} \cdot y_{c i} d A_{c i}+\int_{A_{c o}} \bar{E}_{c o} \cdot \varepsilon_{c o} \cdot y_{c o} d A_{c o}+\sum_{i=1}^{n s} \bar{E}_{s i} \cdot \varepsilon_{s i} A_{s i} y_{s i}$

$M_{y}=\int_{A_{c i}} \bar{E}_{c i} \cdot \varepsilon_{c i} \cdot x_{c i} d A_{c i}+\int_{A_{c o}} \bar{E}_{c o} \cdot \varepsilon_{c o} \cdot x_{c o} d A_{c o}+\sum_{i=1}^{n s} \bar{E}_{s i} \cdot \varepsilon_{s i} A_{s i} x_{s i}$

Where: 
$\bar{E}_{c i}, \bar{E}_{c o}$, concrete secant modulus of elasticity, the subscripts $\left(c_{i}, c_{0}\right)$ are representing the elements of inner and outer concrete layers of the hybrid column, respectively.

$\bar{E}_{s i}$ : steel secant modulus of elasticity for, the subscripts (i) represent the number of steel bar.

$\varepsilon_{c i}, \varepsilon_{c o}:$ strain in concrete elements

$\varepsilon_{s i}$ : strain in the steel bar.

$A_{c i}, A_{c o}$ : area of the concrete element

$A_{s i}$ : area of steel bar.

$n s$ : number of steel bars

$x, y$ : centroidal coordinates for any element in the cross-section.

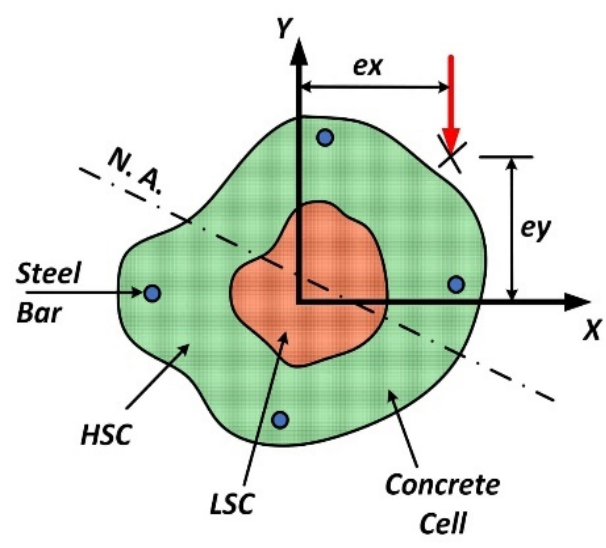

Figure 7. Discrete of hybrid column section.

Throughout the previous assumption, linear distribution of strain across the column section is adopted and Equations 1, 2, and 3 can be re-written as:

$N=\int_{A_{c i}} \bar{E}_{c i}\left(\varepsilon_{0}+\phi_{x} y+\phi_{y} x\right) d A_{c i}+\int_{A_{c o}} \bar{E}_{c o}\left(\varepsilon_{0}+\phi_{x} y+\phi_{y} x\right) d A_{c o}+\sum_{i=1}^{n s} \bar{E}_{s i}\left(\varepsilon_{0}+\phi_{x} y+\phi_{y} x\right) A_{s i}$

$M_{x}=\int_{A_{c i}} \bar{E}_{c i}\left(\varepsilon_{0}+\phi_{x} y+\phi_{y} x\right) y_{c i} d A_{c i}+\int_{A_{c o}} \bar{E}_{c o}\left(\varepsilon_{0}+\phi_{x} y+\phi_{y} x\right) y_{c o} d A_{c o}+\sum_{i=1}^{n s} \bar{E}_{s i}\left(\varepsilon_{0}+\phi_{x} y+\phi_{y} x\right) A_{s i} y_{s i}$

$M_{y}=\int_{A_{c i}} \bar{E}_{c i}\left(\varepsilon_{0}+\phi_{x} y+\phi_{y} x\right) x_{c i} d A_{c i}+\int_{A_{c o}} \bar{E}_{c o}\left(\varepsilon_{0}+\phi_{x} y+\phi_{y} x\right) x_{c o} d A_{c o}+\sum_{i=1}^{n s} \bar{E}_{s i}\left(\varepsilon_{0}+\phi_{x} y+\phi_{y} x\right) A_{s i} x_{s i}$

where:

$\varepsilon_{0}$ : strain at the principal axes.

$\phi_{x}, \phi_{y}$ : curvature concerning $M_{x}, M_{y}$.

These systems of equations can be written in matrix form:

$\left\{\begin{array}{c}N \\ M_{x} \\ M_{y}\end{array}\right\}=\left\{\begin{array}{c}N \\ N . e_{y} \\ N . e_{x}\end{array}\right\}=\left[\begin{array}{lll}c_{11} & c_{12} & c_{13} \\ c_{21} & c_{22} & c_{23} \\ c_{31} & c_{32} & c_{33}\end{array}\right]\left\{\begin{array}{c}\varepsilon_{0} \\ \phi_{x} \\ \phi_{y}\end{array}\right\}$

Where $\left(c_{11}-c_{33}\right)$ are the elements of the stiffness matrix, (ex, ey) are the eccentricities in $\mathrm{x}$ and $\mathrm{y}$-directions; respectively. For isotropic material and by numerical integration, the elements of the stiffness matrix can be written:

$c_{11}=\sum_{K=1}^{n c i} \bar{E}_{c k} A_{c k}+\sum_{K=1}^{n c o} \bar{E}_{c k} A_{c k}+\sum_{i=1}^{n s} \bar{E}_{s i} A_{s i}$ 


$$
\begin{aligned}
& c_{12}=c_{21}=\sum_{k=1}^{n c i} \bar{E}_{c k} A_{c k} y+\sum_{K=1}^{n c o} \bar{E}_{c k} A_{c k} y+\sum_{i=1}^{n s} \bar{E}_{s i} y_{s i} A_{s i} \\
& c_{13}=c_{31}=\sum_{k=1}^{n c i} \bar{E}_{c k} A_{c k} x+\sum_{K=1}^{n c o} \bar{E}_{c k} A_{c k} x+\sum_{i=1}^{n s} \bar{E}_{s i} x_{s i} A_{s i} \\
& c_{22}=\sum_{k=1}^{n c i} \bar{E}_{c k} A_{c k} y^{2}+\sum_{K=1}^{n c i} \bar{E}_{c k} A_{c k} y^{2}+\sum_{i=1}^{n s} \bar{E}_{s i} y_{s i}^{2} A_{s i} \\
& c_{32}=c_{23}=\sum_{k=1}^{n c i} \bar{E}_{c k} A_{c k} y x+\sum_{K=1}^{n c o} \bar{E}_{c k} A_{c k} y x+\sum_{i=1}^{n s} \bar{E}_{s i} y_{s i} x_{s i} A_{s i} \\
& c_{33}=\sum_{k=1}^{n c i} \bar{E}_{c k} A_{c k} x^{2}+\sum_{K=1}^{n c o} \bar{E}_{c k} A_{c k} x^{2}+\sum_{i=1}^{n s} \bar{E}_{s i} x_{s i}^{2} A_{s i}
\end{aligned}
$$

Where:

$\mathrm{nci}, \mathrm{nco}, \mathrm{ns}=$ The number of inner, outer concrete elements and steel bars, respectively.

$c_{11}=$ Axial stiffness which is depending on the axial force.

$c_{12}, c_{21}=$ Axial-flexural stiffness which is depending on axial force and bending moment about of $\mathrm{x}$-axis.

$c_{13}, c_{31}=$ Axial-flexural stiffness which is depending on axial force and bending moment about of $\mathrm{y}$-axis.

$c_{22}:=$ Flexural stiffness which is depending on the bending moment about of the $\mathrm{x}$-axis.

$c_{23}=$ Flexural stiffness which is depending on the bending moment about of the $\mathrm{x}$ and $\mathrm{y}$-axis.

$c_{33}=$ Flexural stiffness which is depending on the bending moment about of the $y$-axis.

Equation 7 can be solved using MATLAB computer programming. In this method, the external load is gradually increased step by step by specified increments. For each load increment, the strain in all concrete cells and all steel bars are determined. The strains in concrete and steel bars are compared with the ultimate strain of materials, if the computed strain results are less than the ultimate strain of materials, a load increment is added. Whereas, if the computed strain is more than the ultimate strain, the load decrease. This procedure is repeated until the convergence. It should be noted, the convergence conditions are established to check the iteration cycles and compare them with allowable incompatibilities. In the present study, the allowable incompatibilities as follows:

For the axial load $(\mathrm{N}),\left(\frac{N_{i}-N_{i-1}}{N_{i}} * 100\right) \leq 0.1$, where $N_{i}$ is computed in the current iteration and $N_{i-1}$ is computed in the previous iteration.

A flow chart of the proposed computer model is shown in Figure 8. The results of the analytical procedure were examined by comparing them with the results of the experimental test program. 


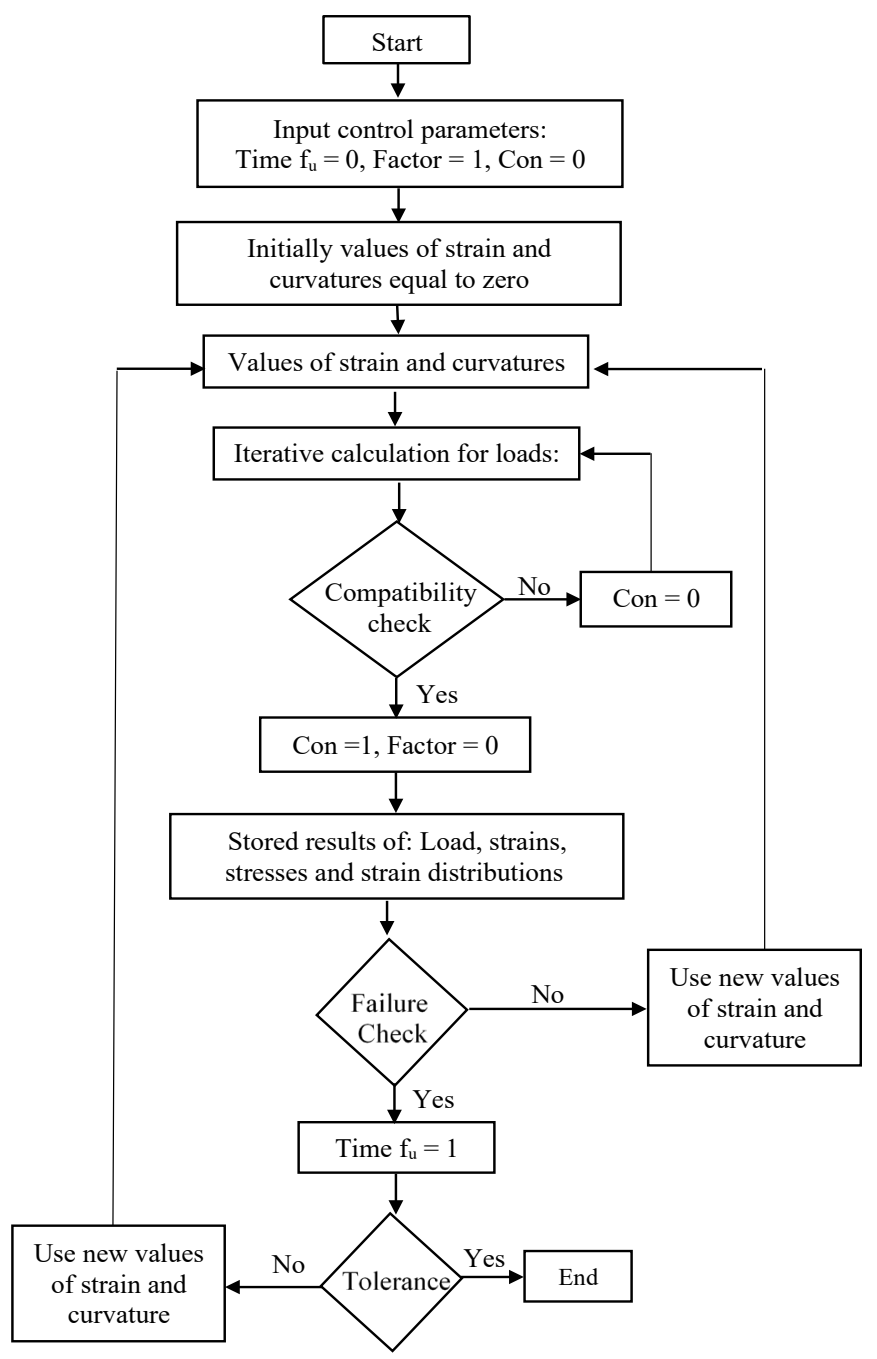

Figure 8. Flowchart of the proposed computer program.

\subsection{Numerical model}

FEA computer program (ABAQUS) was used to model the low-strength, high-strength and hybrid's RC columns. Additionally, the concrete damage plasticity model (CDP) was used to simulate the compressive and tensile behaviour of concrete through adopting the stress-strain curves proposed by Euro code 2 and Belrbi and Hsu (1994), as shown in Figure 9 (a, b). The damage parameters were taken into consideration and they calculated as stress ratios (Kmiecik and Kaminski, 2011). On the other hand, the steel reinforcement was moulded as elastic-plastic material, as shown in Figure 9 (c) (Gu et al., 2016).
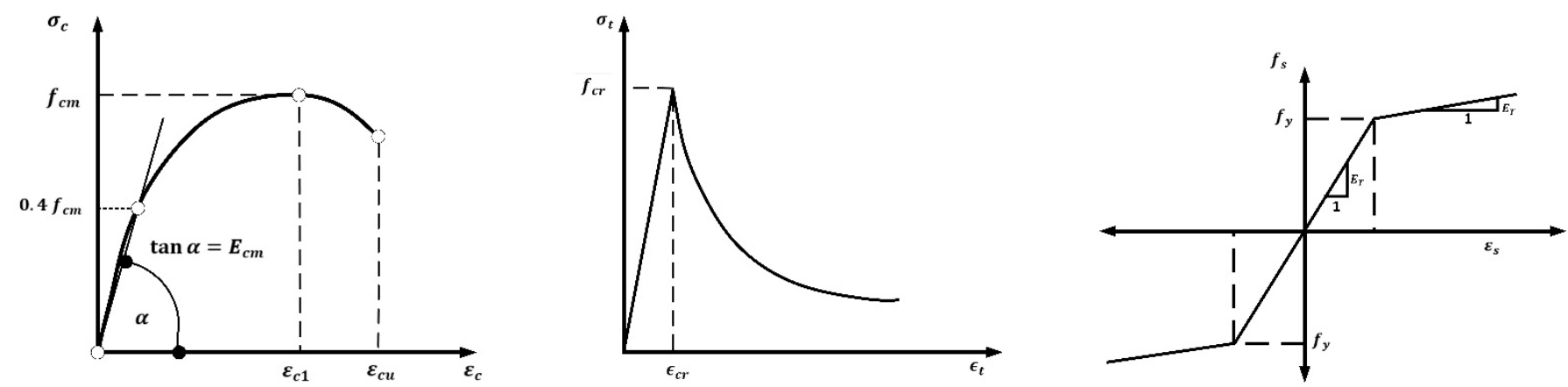

Figure 9. Stress-strain curves for materials: (a) Uniaxial stress-strain diagram of unconfined plain concrete in compression; (b) Tensile stress-strain diagram of plain concrete; (c) Theoretical stress-strain curve of reinforcement (Bilinear Model).

A three-dimensional 8-noded hexahedral element (brick element) with 3 degrees of freedom in each node (C3D8R) was used for concrete modelling. This element has a 1-integration point. Besides, steel reinforcement was modelled with a 2-noded truss element (T3D2) having 3 degrees of freedom in each node assuming a full bond between concrete and 
steel bars by embedding the reinforcement element into the concrete elements. Two reference points (RP) were created at the top and bottom surfaces for each RC column with eccentricity equal to $50 \mathrm{~mm}(\mathrm{e} / \mathrm{h}=0.4)$. A coupling constraint was used between each reference point and the top and bottom surface. The load was applied as a velocity equal to $80 \mathrm{~mm} / \mathrm{s}$ at the top reference point. Besides, all displacements in the $x, y$, and $z$-plane were constrained except the axial displacement at the top reference point. However, rotation around these axes was allowed. Finally, in hybrid column specimens, the two types of concrete were constrained at the interface surface by tie constraint (master-slave type). Figure 10 displayed the loading, boundary conditions, meshing, and finite elements used in the hybrid column specimen. Table 3 shows the types of finite elements used in this study.

Table 3. Types of finite elements used

\begin{tabular}{cc}
\hline Types of Materials & ABAQUS Element \\
\hline Concrete (class $23 \mathrm{MPa}$ ) & Standard 8-node linear brick element with reduced interaction \\
Concrete (class $50 \mathrm{MPa}$ ) & T3D2 standard 2-node linear Truss in space \\
Longitudinal steel bars & T3D2 standard 2-node linear Truss in space \\
\hline Lateral steel bars & \\
\hline
\end{tabular}

ABAQUS-Dynamic Explicit Procedure (DEP) was used in the FEA of the column specimens with a total time equal to 1sec. It solves the dynamic equilibrium formula without an iterative process by utilizing the central difference method to solve nonlinear problems. The dynamic explicit technique needs small time increments so that the time incrementation is fully automatic and needs no user intervention. The term dynamic explicit analysis refers to the solution of the dynamic equilibrium equation by quasistatic analysis in which the loading is applied so that inertia effects become insignificant.

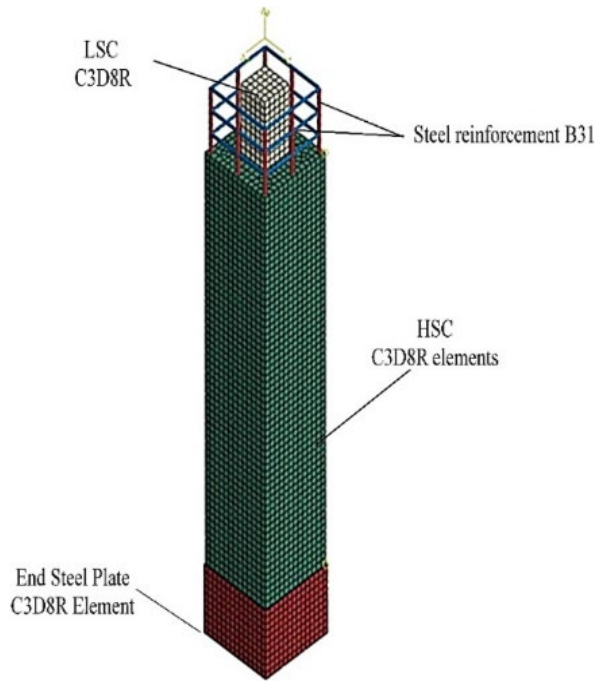

Figure 10. Finite element simulation of HC specimen.

\section{RESULTS, EVALUATIONS AND DISCUSSIONS}

\subsection{Experimental, analytical and numerical results}

Table 4 shows the ultimate load capacity obtained by experimental work (PExp), analytical proposed program (PAna) and finite element analysis via the ABAQUS program (PFEA). Table 4 shows a good agreement in ultimate loads PFEA and PAna when compared with those recorded experimentally, where the values of $\frac{P_{F E A}}{P_{E X P}}$ and $\frac{P_{A n a}}{P_{E X P}}$ were close to one, especially for FEA. Unfortunately, this good agreement couldn't be seen in axial deformation $(\Delta)$ results. This is maybe attributed to the difficulty of obtaining accurate deformation measurements through the testing activities.

The results show an increase in the load capacity of hybrid columns with a decrease in the hybrid's ratio. Experimentally, the ultimate load capacity of hybrid column HY.16 equal to $702 \mathrm{kN}$ which is more than $38 \%$ and $9 \%$ as compared with those obtained by HY.36 and HY.25, respectively, and less by $10 \%$ as compared with the HSC column. The column stiffness was improved with decreasing of hybrid's ratio due to an increase in the cross-sectional area of HSC and reduction of LSC. 
Table 4. Comparison among experimental, analytical and numerical results

\begin{tabular}{|c|c|c|c|c|c|c|c|c|}
\hline \multirow{3}{*}{ Column ID. } & \multirow{2}{*}{\multicolumn{2}{|c|}{ Experimental results }} & \multicolumn{2}{|c|}{ Analytical } & \multicolumn{4}{|c|}{ FEA } \\
\hline & & & \multirow{2}{*}{$\begin{array}{c}\text { Results } \\
P_{\text {Ana }}(k N) \\
\end{array}$} & \multirow{2}{*}{$\begin{array}{c}\text { Comparison } \\
P_{\text {Ana }} / P_{\text {EXP }} \\
\end{array}$} & \multicolumn{2}{|c|}{ Results } & \multicolumn{2}{|c|}{ Comparison } \\
\hline & $P_{\text {EXP }}(k N)$ & $\Delta_{\mathrm{EXP}}(\mathrm{mm})$ & & & $\mathrm{P}_{\mathrm{FE}}(\mathrm{kN})$ & $\Delta_{\mathrm{FEA}}(\mathrm{mm})$ & $P_{\mathrm{FEA}} / \mathrm{P}_{\mathrm{EXP}}$ & $\Delta_{\mathrm{FEA}} / \Delta_{\mathrm{EXP}}$ \\
\hline LSC & 430 & 2.1 & 540 & 1.26 & 407 & 2.53 & 0.95 & 1.20 \\
\hline HY.36 & 510 & 2.6 & 555 & 1.09 & 450 & 2.25 & 0.88 & 0.87 \\
\hline HY.25 & 646 & 3.1 & 581 & 0.90 & 587 & 2.46 & 0.91 & 1.26 \\
\hline HY.16 & 702 & 2.8 & 616 & 0.88 & 660 & 2.67 & 0.94 & 0.95 \\
\hline $\mathrm{HSC}$ & 780 & 3.0 & 652 & 0.85 & 726 & 2.39 & 0.93 & 0.80 \\
\hline
\end{tabular}

Moreover, the maximum load capacities of hybrid columns were compared with those obtained by conventional columns, as shown in Table 5. The values of the comparison were increased when the strength LSC was chosen as reference columns. Conversely, these values were decreased when compared with HSC. Certainly, the column stiffness was improved with decreasing of hybrid's ratio due to an increase in the cross-sectional area of HSC and reduction of LSC area.

Table 5. Normalize the ultimate load with the strength of conventional columns

\begin{tabular}{|c|c|c|c|}
\hline \multirow{2}{*}{ Column ID. } & \multirow{2}{*}{$\frac{\mathbf{P}_{\mathrm{TEST}}}{\mathrm{kN}}$} & \multicolumn{2}{|c|}{ Comparssion Ratio } \\
\hline & & $\mathrm{P}_{\mathrm{TEST}} / \mathrm{P}_{\mathrm{LSC}}$ & $\mathbf{P}_{\text {TEST }} / \mathbf{P}_{\text {HSC }}$ \\
\hline LSC & 430 & 1 & 0.55 \\
\hline HY.36 & 510 & 1.18 & 0.65 \\
\hline HY.25 & 646 & 1.5 & 0.82 \\
\hline HY.16 & 702 & 1.63 & 0.9 \\
\hline $\mathrm{HSC}$ & 780 & 1.81 & 1 \\
\hline
\end{tabular}

The final collapse mode of the tested columns and FE models were displayed in Figure 11. All column specimens were failed in compression failure mode. FE Failure mode was represented as the compression damage parameter (dc) of concrete under biaxial loading. The values of dc ranging between 0 for undamaged concrete (with blue colour) and 0.8 for complete damage of concrete (with red colour). Some extent of similarity can be seen between numerical failure modes and the corresponding experimental ones.

The experimental results of load-strain curves of a concrete and longitudinal steel bar of all tested specimens are presented in Figure 12 with a negative sign for compressive strains and a positive sign for tensile strains. Besides, Figure 13 shows the comparison between the load-axial strain relationships obtained from nonlinear FEA and those measured from tested specimens. In general, the strain is decreased with a decrease in the hybrid's ratio of the specimen because of the increase in modulus of elasticity due to the increase in the amount of HS concrete with the decrease of the hybrid's ratio. When the load is applied, the amount of strain was slightly increased. In general, the strains were small at the elastic stage of loading, then they increased steadily with the loading progress. Consequently, micro cracks were formed. At the last stage of loading, at least one of the strainload curves for concrete or steel tends to transition to the descending part but the failure has occurred.

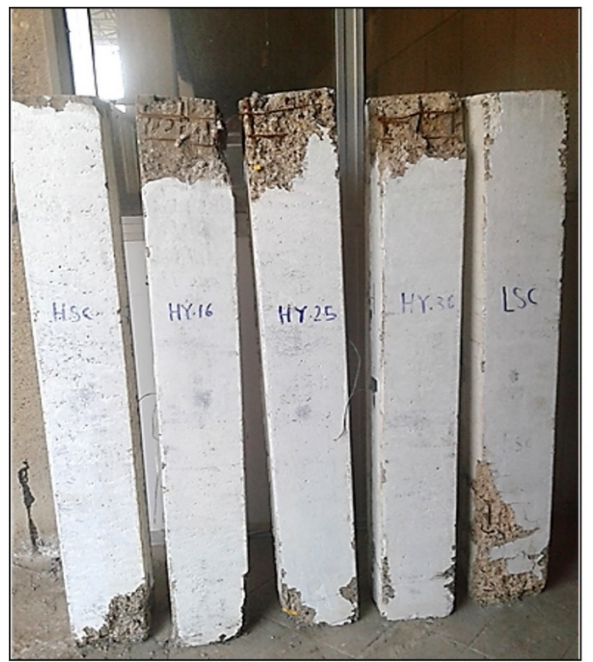

(a)
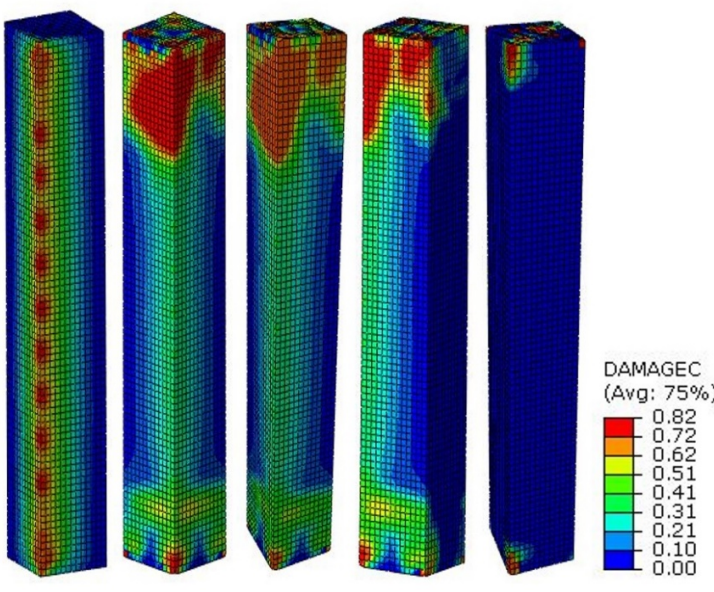

(b)

Figure 11. Experimental and numerical failure modes of RC hybrid columns: (a) Failure modes of tested specimens; (b) Failure modes of the corresponding FE models. 

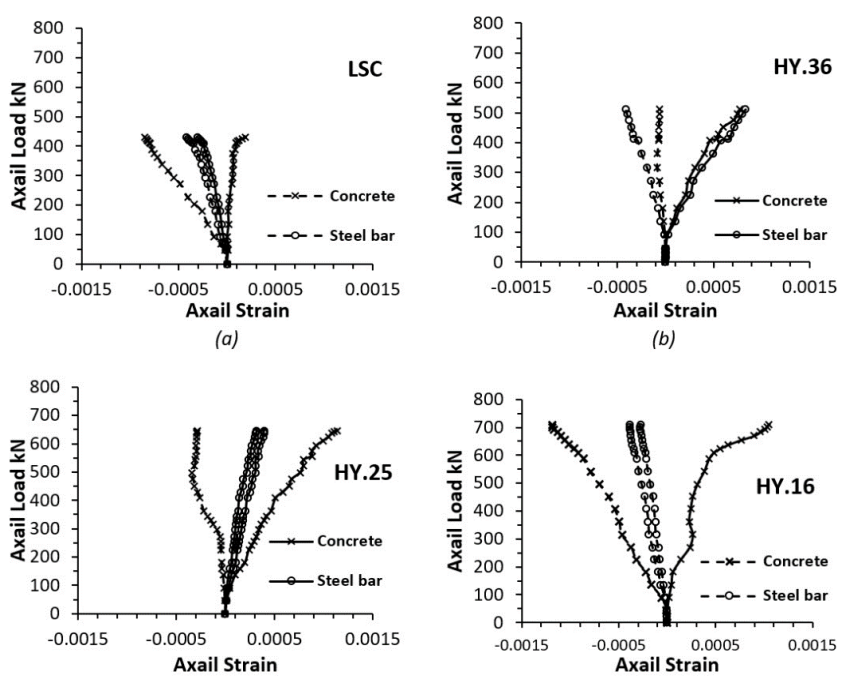

(c)

(d)

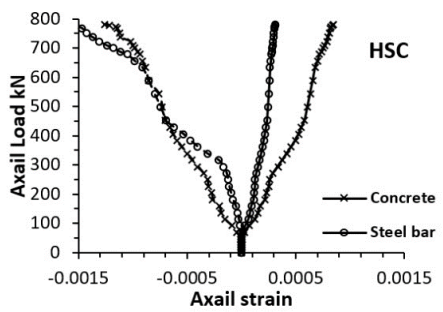

(e)

Figure 12. Experimental load-strain curves of RC column specimens: (a) LSC; (b) HY.36; (c) HY.25; (d) HY.16; (e) HSC.

The ductility index was calculated according to (Park, 1989). It is calculated as a ratio of the axial deformation at maximum load $(\Delta)$ to the deformation at the yield $(\Delta y)$. It was observed when the hybrid's ratio decreases from 0.36 to 0.16 the ductility index was reduced. This is occurred due to the increase of column stiffness, as shown in Figure 14.
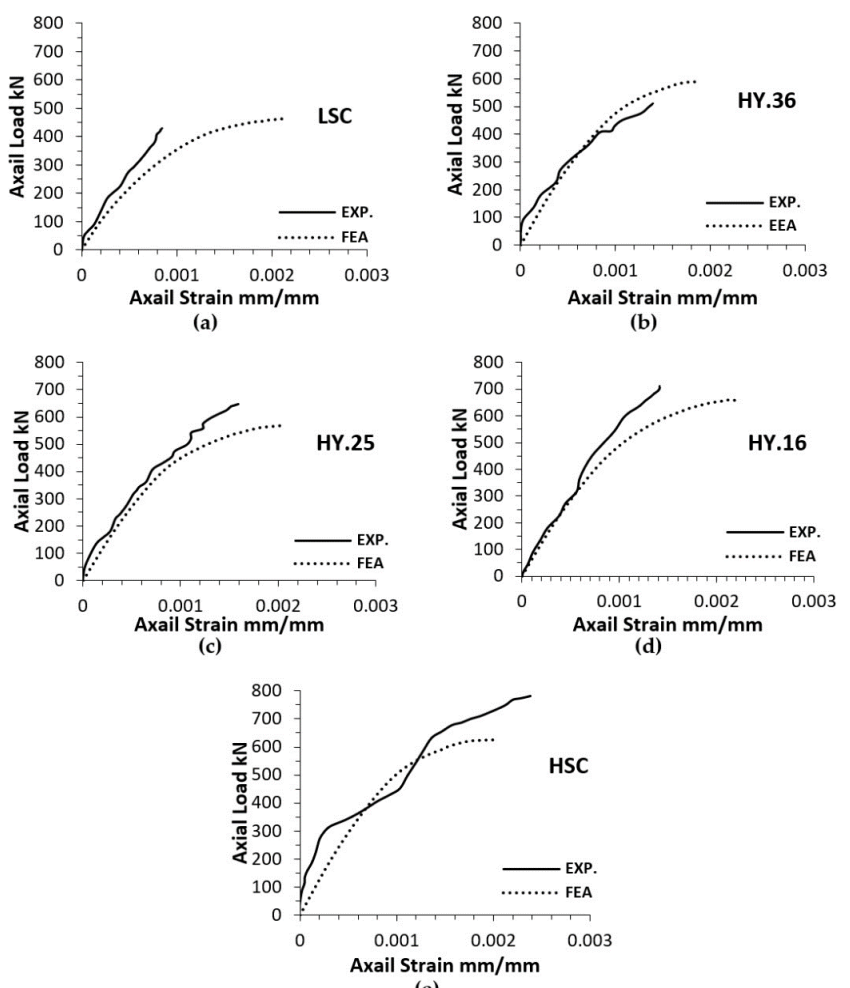

(d)

Figure 13. Numerical and experimental load-strain curve of RC column specimens: (a) LSC; (b) HY.36; (c) HY.25; (d) HY.16; (e) HSC. 


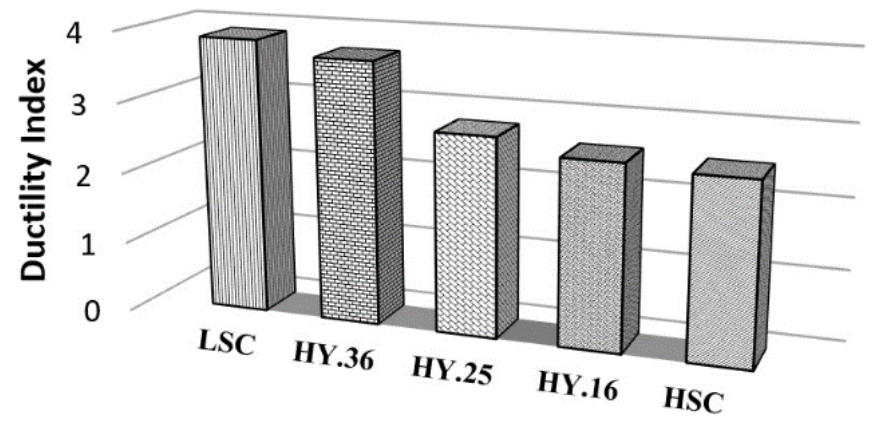

Figure 14. Ductility index of tested specimens.

\subsection{Analytical and numerical models' evaluation}

Table 6 indicates that the load capacity predicted by the analytical and numerical models is reliable based on the experimental outcomes. These models estimate resulted in mean values of (1.030 and 1.09), SDs of (0.17 and 0.03$)$, and CoVs of (16.3\% and $2.9 \%)$ for analytical and numerical models, respectively, thus confirming their accuracy and consistency. Figure 15 shows comparisons of load capacity between experimental data and those obtained from models' prediction and indicates that the predicted models are generally dependable. One study by Gomes (2000) stated that the value of a CoV reflects the accuracy of the relationship between the inputs and the target, where CoV values of less than 10\%, 20-30\%, and above 30\% mean high accuracy, low accuracy and low precision, respectively. For the numerical model, the CoV was $2.9 \%$, indicating high accuracy, as compared with the analytical model. Moreover, the R-value of 0.9681 (as presented in Table 6) reflect the good agreement between the actual and predicted load capacities. It can be stated based on these findings that the numerical model efficiently estimates the load capacity values of reinforced hybrid concrete columns under biaxial loading.

Table 6. Statistical parameters of the predicted models for extra validation

\begin{tabular}{|c|c|c|c|c|}
\hline Item & Formula & Condition & Ana & FEA \\
\hline & 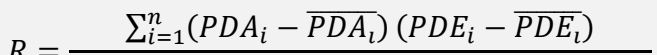 & & & \\
\hline 1 & 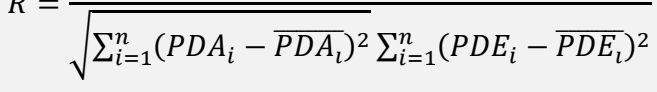 & $R>0.8$ & 0.9681 & 0.9949 \\
\hline 2 & $k=\frac{\sum_{i=1}^{n}\left(P D A_{i} \times P D E_{i}\right)}{P D A_{i}^{2}}$ & $0.85<k<1.15$ & 0.84 & 0.93 \\
\hline 3 & $\hat{k}=\frac{\sum_{i=1}^{n}\left(P D A_{i} \times P D E_{i}\right)}{P D E_{i}^{2}}$ & $0.85<k^{\prime}<1.15$ & 1.20 & 1.07 \\
\hline 4 & $R_{m}=R^{2} \times\left(1-\sqrt{\left|R^{2}-R_{o}^{2}\right|}\right)$ & $R_{m}>0.5$ & 5.63 & 0.52 \\
\hline
\end{tabular}

Were,

$R_{o}^{2}=1-\frac{\sum_{i=1}^{n}\left(P D E_{i}-P D A_{i}^{o}\right)^{2}}{\left(P D E_{i}-\overline{P D E_{\imath}}\right)^{2}}, P D A_{i}^{o}=k \times P D E_{i}$ 


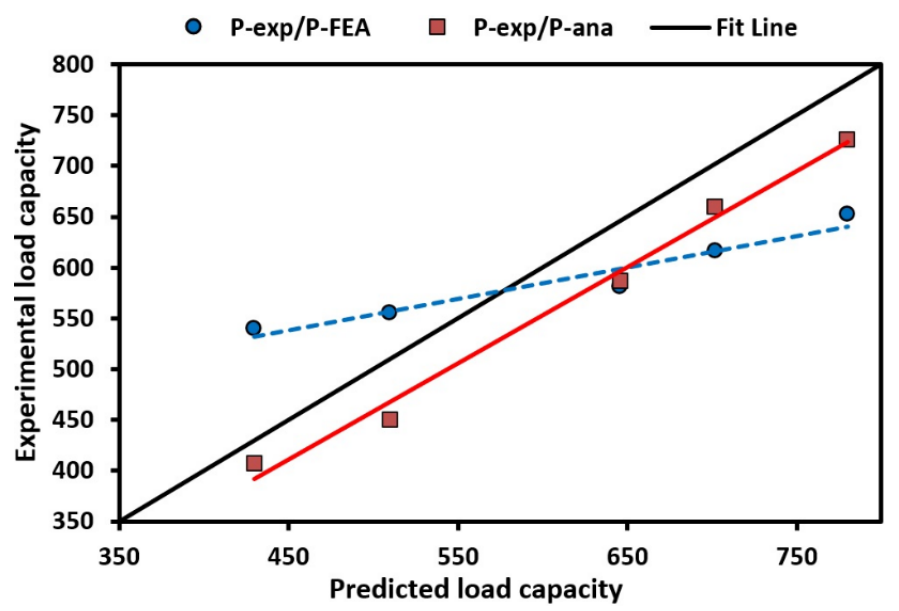

Figure 15. Comparisons among predicted and experimental load capacity values of reinforced hybrid concrete columns under biaxial loading.

Furthermore, the criterion recommended by Golbraikh and Tropsha (2002) was used for the external verification of the predicted models on the experimental datasets. At least one slope of regression lines ( $k$ or $\left.k^{\prime}\right)$ through the origin should be close to 1 (Gandomi and Alavi, 2013). Roy and Roy (2008) introduced a confirmative indicator of the external predictability of models $(\mathrm{Rm})$. For $\mathrm{R} \_\mathrm{m}>0: 5$, the condition is satisfied. The squared correlation coefficient (through the origin) between predicted and experimental values $\left(R_{-} o^{\wedge} 2\right)$ should be close to 1 . The validation criteria and the relevant results obtained by the model are presented in Table 6 . As can be seen, the predicted models satisfy the abovementioned criteria. The load capacity value predictions made by the predicted models are presented in Figure 16 . A model has good prediction accuracy when the ratio of the experimental load capacity to predicted load capacity is equal to one. Figure 16 indicates that the distribution of the ratio of the experimental to predicted load capacities confirms the model's high prediction accuracy.

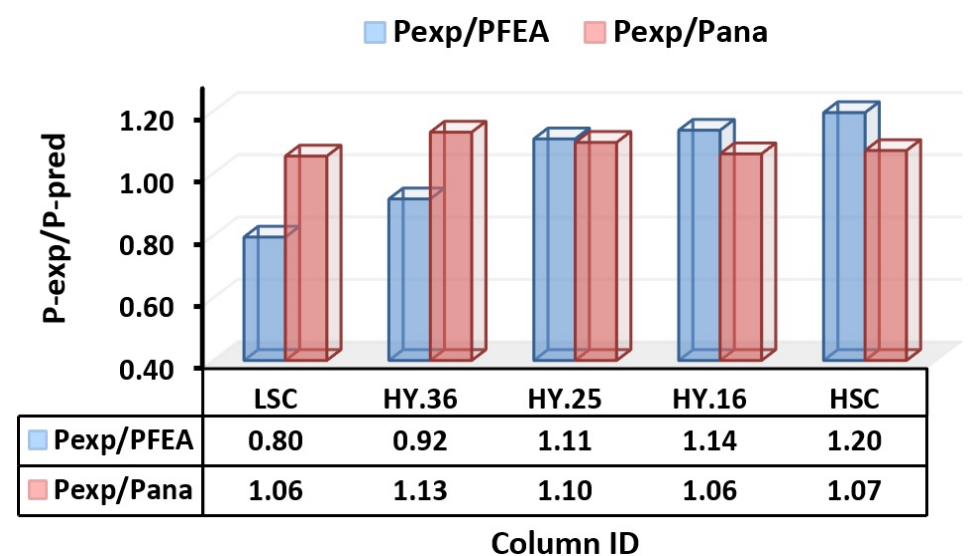

Figure 16. Comparison between the predicted and experimental load capacity values of reinforced hybrid concrete columns under biaxial loading using the predicted models.

Sometimes, the correlation coefficient, $\mathrm{R}$, is not a suitable indicator for an accurate prediction, as it does not respond to the changes due to multiplication or addition by a constant in the output values. Thus, to assess the model power, an error approach should be utilized in conjunction with the R values. A proposed performance evaluation function by [48] considering the changes in correlation and error functions. The performance index, $\mathrm{PI}$, was used based on the function to evaluate performance as a function of the correlation coefficient, R, and relative root mean square error, RRMSE, and as follows:

$P I=\frac{R R M S E}{R+1}$

$R R M S E=\frac{1}{\left|\overline{P A}_{i}\right|} \sqrt{\frac{\sum_{i=1}^{n}\left(P A_{i}-P E_{i}\right)^{2}}{n}}$ 
$R=\frac{\sum_{i=1}^{n}\left(P A_{i}-\overline{P A}\right)\left(P E_{i}-\overline{P E}\right)}{\sqrt{\sum_{i=1}^{n}\left(P A_{i}-\overline{P A}\right)^{2} \sum_{i=1}^{n}\left(P E_{i}-\overline{P E}\right)^{2}}}$

Where $P A_{i}$ and $P E_{i}$ are the ith observed and forecast outputs, respectively; $\overline{P A}$ and $\overline{P E}$ represents the average values of the observed and forecast response, respectively while $n$ denotes the number of samples.

Higher R values and lower RRMSE values lead to lower PI and, consequently, indicate a more precise model. According to the $\mathrm{PI}$ expression, the $\mathrm{PI}$ value range is 0 to $+\infty$. For the proposed performance index, a $\mathrm{PI}$ value close to zero denotes higher accuracy and better acceptance of the proposed model. As discussed previously, the analytical and numerical models were obtained to predict the load capacity values of reinforced hybrid concrete columns under biaxial loading. The overall statistical performance of the modified model is summarized in Table 7. The performance of these models displayed the best (highest) $R$ values with the best (lowest) RRMSE values among all models, especially for the numerical model. Thus, based on statistical principles, the FEA model has a good correlation and covariance as well as an adequate $\mathrm{PI}$ value, as compared with the other model.

Table 7. Overall performances of the models for the load capacity values of reinforced hybrid concrete columns

\begin{tabular}{cccc}
\hline \multirow{2}{*}{ Model } & \multicolumn{3}{c}{ Experimental vs. predicted } \\
\cline { 2 - 4 } & RRMSE & R & PI \\
\hline Analytical & 91.79 & 0.9681 & 46.64 \\
FEA & 49.58 & 0.9949 & 24.85 \\
\hline
\end{tabular}

\subsection{Strength-interaction curves}

The strength of Hybrid columns exposed to biaxial loading can be illustrated by strength interaction diagrams based on the proposed program that was written in MATLAB software, as shown in Section 3. The strength-interaction diagrams of hybrid columns (HY.16, HY.25 and HY.36) were plotted in Figure 14 with dashed lines while the solid lines represent the conventional columns LSC and HSC. The load eccentricities in both directions were identical, i.e., ex $=\mathrm{ey}, \lambda=\tan ^{-1}\left(\mathrm{e}_{\mathrm{y}} / \mathrm{e}_{\mathrm{x}}\right)=45 \mathrm{o}$, these eccentricities were increased from zero to $100 \mathrm{~mm}$ for each column specimen. The ultimate compression load for the pure compression case was calculated based on ACI318-19 as follow:

$N=0.85 f_{c o}^{\prime}\left(A_{g o}-A_{s}\right)+f_{y} A_{s}+0.85 f_{c i}^{\prime} A_{g i}$

Where,

$f_{c o}^{\prime}, f_{c i}^{\prime}$ : Specified compressive strength of outer concrete and inner concrete.

$A_{g o}, A_{g i}:$ Gross area of outer concrete and inner concrete.

$A_{s}$ : Area of longitudinal reinforcement.

$f_{y}$ : Specified yield strength for reinforcement.

In addition, strength-interaction curves were plotted to represent the strength combination at which $N$ and $M_{x}, M_{y}$ act together. With the increase of hybrid's ratio, the ultimate capacity is decreased due to the reduction of column stiffness. This actually can be attributed to the increasing dimensions of the inner core of LS concrete and the reduction in HS concrete area at the outer layer. The experimental load-moment capacities were projected on the interaction diagram that predicted from the analytical study. All experimental values of load-moment points (Exp.) fell outside the failure surface obtained by the proposed program, except the HY.36 specimen as shown in Figure 17. This finding indicates the conservation of the proposed analytical method. 


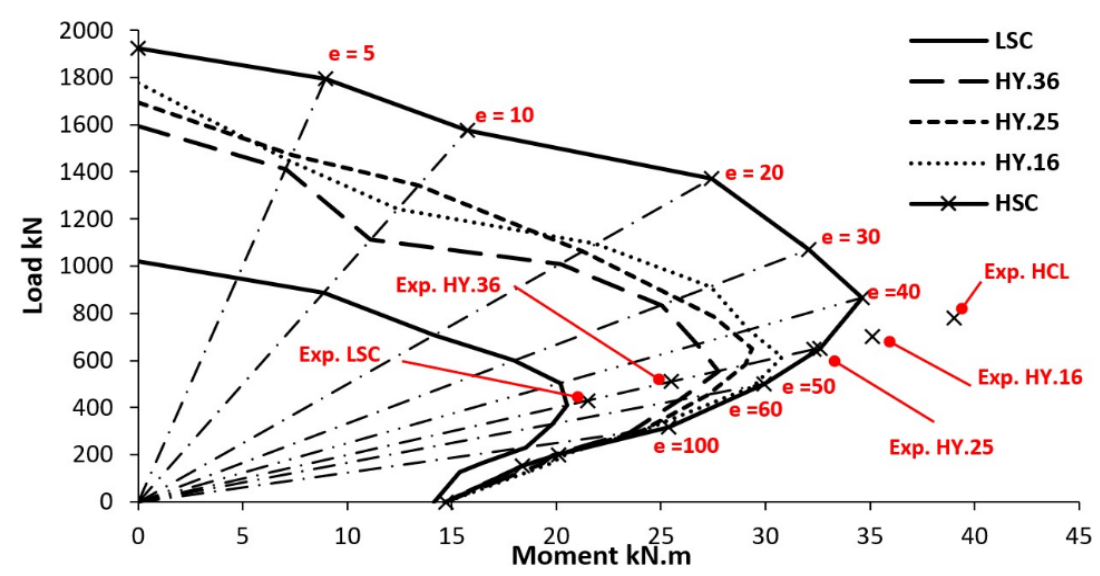

Figure 17. Interaction diagrams of hybrid column specimens (e in $\mathrm{mm}$ )

\section{CONCLUSIONS}

In this paper, hybrid concrete column specimens were fabricated from two types of concrete so that the low strength inner concrete was enclosed by the high strength concrete with a full bond between them. These specimens were tested under biaxial compressing load. The testing of columns considered the effect of the hybrid's ratio on the ultimate capacity and axial deformation of the columns. Besides, numerical and analytical analyses were executed to enrich the investigation of the influence of the hybrid's ratio on the column performance. The experimental, analytical and numerical studies yielded the following conclusions:

1. All column specimens were failed in compression.

2. The strength of the column increased by $38 \%$ with the decrease of the hybrid's ratio from 0.36 to 0.16 .

3. At a specific loading level, the axial strain was decreased with decreasing of the hybrid's ratio of the specimen.

4. The ductility index was improved by $64 \%$ with an increase of hybrid's ratios from 0.16 to 0.36 .

5. Hybrid columns with a small hybrid's ratio resist more axial load and bending moments with different load eccentricity as compared with hybrid column has a large value of the hybrid's ratio.

6. The coefficient of variation (CoV), and correlation coefficient (R2) values were $2.9 \%$ and 0.9681 for the numerical model, respectively, which showed the good accuracy and consistency of the obtained values, as compared with the analytical model. Moreover, the performance index, $(\mathrm{PI})$ value of 24.85 reflects a good agreement between the actual and predicted ultimate load capacities. It can be stated according to these findings that the numerical model efficiently estimates the ultimate load capacity of reinforced hybrid concrete columns under biaxial loading.

\section{Acknowledgements}

The authors would like to offer real thanks and appreciation to the staff of the Civil Engineering Department, College of Engineering / University of Baghdad for their support and encouragement.

Author Contributions: Conceptualization, A H Al-Zuhairi, A H Al-Ahmed, A N Hanoon and A A Abdulhameed; Data curation, A H Al-Zuhairi, A N Hanoon and A A Abdulhameed; Formal Analysis, A H Al-Zuhairi, A N Hanoon and A A Abdulhameed; Funding acquisition, A H Al-Zuhairi, A A Abdulhameed; Investigation, A H Al-Zuhairi, A N Hanoon and A A Abdulhameed; Methodology, A H Al-Zuhairi, A H Al-Ahmed, A N Hanoon and A A Abdulhameed; Project administration, A H Al-Zuhairi and A A Abdulhameed; Resources, A H Al-Zuhairi and A A Abdulhameed; Software, A H Al-Ahmed and A N Hanoon; Supervision, A H Al-Zuhairi and A A Abdulhameed; Validation, A H Al-Zuhairi, A H Al-Ahmed, A N Hanoon and A A Abdulhameed; Writing - original draft preparation, A H Al-Zuhairi, A H Al-Ahmed, A N Hanoon and A A Abdulhameed; Writing - review \& editing, A H Al-Zuhairi and A A Abdulhameed.

Editor: Marcílio Alves. 


\section{References}

Abdualrahman, S. Q., \& Al-Zuhairi, A. H. (2020). A Comparative Study of the Performance of Slender Reinforced Concrete Columns with Different Cross-Sectional Shapes. Fibers, 8(6), 35.

Abdualrahman, S. Q., \& Al-Zuhairi, A. H. (2020, July). Structural Performance of Slender RC Columns with Cross and SquareShaped under Compression Load. In IOP Conference Series: Materials Science and Engineering (Vol. 881, No. 1, p. 012040). IOP Publishing.

Abdulhameed, A. A., \& Said, A. I. (2019). Experimental Investigation of the Behavior of Self-Form Segmental Concrete Masonry Arches. Fibers, 7(7), 58.

ACl 318-19, Building Code Requirements for Structural Concrete and Commentary, Farmington Hills, Michigan: American Concrete Institute; 2019.

Ali, T. K. M. (2020). Experimental Behavior and Analysis of Hybrid Low-High Strength Reinforced Concrete Columns. Journal of Materials and Engineering Structures «JMES», 7(2), 203-214.

Alshimmeri, A. J. H. (2016). Structural Behavior of Confined Concrete Filled Aluminum Tubular (CFT) Columns under Concentric Load. Journal of Engineering, 22(8), 125-139.

American Concrete Institute, "Guide for Selecting Proportions for High-Strength Concrete with Portland Cement and Fly Ash", ACl 211.4R-2017.

American Concrete Institute, "Standard Practice for Selecting Proportions for Normal, Heavyweight, and Mass Concrete", ACl 211.1R-2017.

ASTM C39-18, "Standard Test Method for Compressive Strength of Cylindrical Concrete Specimens", Annual Book of ASTM Standards, American Society for Testing and Materials, Philadelphia, Pennsylvania, Section 4, V. 4.02, 2014.

ASTM C469-14, "Standard Test Method for Static Modulus of Elasticity and Poison's Ratio of Concrete in Compression", Annual Book of ASTM Standards, American Society for Testing and Materials, Philadelphia, Pennsylvania, Section 4, V. $4.02,2014$.

ASTM C496-18, "Standard Test Method for Splitting Tensile Strength of Cylindrical Concrete Specimens", Annual Book of ASTM Standards, American Society for Testing and Materials, Philadelphia, Pennsylvania, Section 4, V. 4.02, 2014.

Belarbi, A., \& Hsu, T. T. (1994). Constitutive laws of concrete in tension and reinforcing bars stiffened by concrete. Structural Journal, 91(4), 465-474.

Bouafia, Y., Iddir, A., Kachi, M. S., \& Dumontet, H. (2014). Stress-strain relationship for the confined concrete. Stress (MPa), 70, 80.

BS 4449,1997, " Specification for Carbon steel bars for the reinforcement of concrete.

Dybet, P., \& Watach, D. (2017, October). Evaluation of the development of bond strength between two concrete layers. In IOP Conference Series: Materials Science and Engineering (Vol. 245, No. 3, p. 032056). IOP Publishing.

Gandomi, A. H., \& Alavi, A. H. (2013). Expression programming techniques for formulation of structural engineering systems (Vol. 18). chapter.

Golbraikh, A., \& Tropsha, A. (2002). Beware of q2!. Journal of molecular graphics and modelling, 20(4), 269-276.

Gu, X., Jin, X., \& Zhou, Y. (2016). Basic principles of concrete structures. Springer Berlin Heidelberg.

Hadi, M. N. S., \& Le, T. D. (2014). Behaviour of hollow core square reinforced concrete columns wrapped with CFRP with different fibre orientations. Construction and Building Materials, 50, 62-73.

Hamid, M. M., Yassin, L. A., \& Mohammed, A. H. (2020, February). Behavior of hybrid reinforced concrete columns. In IOP Conference Series: Materials Science and Engineering (Vol. 737, No. 1, p. 012033). IOP Publishing.

Han, L. H., Liao, F. Y., Tao, Z., \& Hong, Z. (2009). Performance of concrete-filled steel tube reinforced concrete columns subjected to cyclic bending. Journal of Constructional Steel Research, 65(8-9), 1607-1616.

Hsu, C. T. T. (1989). T-shaped reinforced concrete members under biaxial bending and axial compression. Structural Journal, 86(4), 460-468.

Kmiecik, P., \& Kaminski, M. (2011). Modelling of reinforced concrete structures and composite structures with concrete strength degradation taken into consideration. Archives of civil and mechanical engineering, 11(3), 623-636. 
Mander, J. B., Priestley, M. J., \& Park, R. (1988). Theoretical stress-strain model for confined concrete. Journal of structural engineering, 114(8), 1804-1826.

Park, R. (1988, August). Ductility evaluation from laboratory and analytical testing. In Proceedings of the 9th world conference on earthquake engineering, Tokyo-Kyoto, Japan (Vol. 8, pp. 605-616).

Park, R. (1989). Evaluation of ductility of structures and structural assemblages from laboratory testing. Bulletin of the new Zealand society for earthquake engineering, 22(3), 155-166.

Pimentel-Gomes, F. (2000). Course of experimental statistics. Piracicaba: FEALQ, 15.

Resheq, A. (2018). Behaviour of hybrid concrete columns under axial compression loads. In MATEC Web of Conferences (Vol. 162, p. 04021). EDP Sciences.

Roy, P. P., \& Roy, K. (2008). On some aspects of variable selection for partial least squares regression models. QSAR \& Combinatorial Science, 27(3), 302-313.

Wu, X., Kang, T.H.K., Mpalla, I.B. and Kim, C.S., 2018. Axial load testing of hybrid concrete columns consisting of UHPFRC tube and normal-strength concrete core. International Journal of Concrete Structures and Materials, 12(1), pp.1-13.

Yuan, H., Hong, H. P., Deng, H., \& Bai, Y. (2018). Displacement ductility of staged construction-steel tube-reinforced concrete columns. Construction and Building Materials, 188, 1137-1148. 